\title{
Physicians' knowledge, beliefs, and use of race and human genetic variation: new measures and insights
}

Vence L Bonham ${ }^{1 * \dagger}$, Sherrill L Sellers ${ }^{2^{*}}$ and Sam Woolford ${ }^{3}$

\begin{abstract}
Background: Understanding physician perspectives on the intersection of race and genomics in clinical decision making is critical as personalized medicine and genomics become more integrated in health care services. There is a paucity of literature in the United States of America (USA) and globally regarding how health care providers understand and use information about race, ethnicity and genetic variation in their clinical decision making. This paper describes the development of three scales related to addressing this gap in the literature: the Bonham and Sellers Genetic Variation Knowledge Assessment Index-GKAl, Health Professionals Beliefs about Race-HPBR, and Racial Attributes in Clinical Evaluation-RACE scales.

Methods: A cross-sectional, web survey of a national random sample of general internists in the USA ( $N=787)$ was conducted. Confirmatory factor analysis was used to assess the construct validity of the scales. Scale items were developed through focus groups, cognitive interviews, expert advisory panels, and exploratory factor analysis of pilot data.

Results: GKAl was measured as a count of correct answers (Mean $=3.28 \mathrm{SD}=1.17$ ). HPBR yielded two domains: beliefs about race as a biological phenomenon (HPBR-BD, alpha $=.69,4$ items) and beliefs about the clinical value of race and genetic variation for understanding risk for disease (HPBR-CD alpha $=.61,3$ items). RACE yielded one factor (alpha $=.86,7$ items).

Conclusions: GKAl is a timely knowledge scale that can be used to assess health professional knowledge of race and human genetic variation. HPBR is a promising new tool for assessing health professionals' beliefs about the role of race and its relationship with human genetic variation in clinical practice. RACE offers a valid and reliable tool for assessing explicit use of racial attributes in clinical decision making.
\end{abstract}

Keywords: Scale development, Medical decision making, Personalized medicine, RACE (Racial Attributes in Clinical Evaluation), GKAl (Genetic Variation Knowledge Assessment Index), Explicit use of race

\section{Background}

It is well documented that the use of race and ethnicity as surrogate markers for describing one's risk for disease on a genomic level is common in both clinical practice [1] and research settings [2-7]. The utility of race to predict ancestry, genetic population groups and outcomes

\footnotetext{
*Correspondence: bonhamv@nhgri.nih.gov; slsellers@miamioh.edu

${ }^{\dagger}$ Equal contributors

'Social and Behavioral Research Branch, National Human Genome Research Institute, National Institutes of Health, 31 Center Drive, Bethesda, MD 20892, USA ${ }^{2}$ University Department of Family Studies \& Social Work, Miami University, 210 East Spring Street, Oxford, OH 45056, USA

Full list of author information is available at the end of the article
}

of treatment in clinical practice within the USA has been described by Barr as the "practitioner's dilemma: can health care providers use a patient's race to predict genetic variation, ancestry and outcomes in treatment?" [8]. We provide researchers with new survey measures to study physicians' explicit use of patient's race in clinical care, particularly to study health care providers' knowledge of genetic variation, beliefs about race and genetic differences and explicit use of race in clinical decision making.

New scientific knowledge of human genetic variation is facilitating an understanding of why susceptibility to common diseases varies among individuals and populations 
often described by race and ethnicity [9]. Current data refute the notion that 'races' and 'ethnicities' are genetically distinct human populations as no sharp genetic boundaries can be drawn between human population groups [10]. Self-identified race and ethnicity correlate with "genetic population groups" but do not necessarily correlate with an individual's distinct genetic background $[11,12]$. Thus, there is some confusion and debate as to the relationships between risk of diseases and selfidentified race [13-15].

Some researchers argue that racial and ethnic categories can serve as useful variables to investigate the genetic component of disease and patients' responses to treatment, while others contest the utility of race for understanding genetic variation $[14,16]$. Many social scientists and health services researchers believe that the study of race is necessary to understand the social determinants of health $[17,18]$. However, many are concerned that if physicians rely on race as a proxy for genetic risk, this could exacerbate racial and ethnic healthcare disparities in the USA and may even lead to poorer quality of care for all patients $[13,19,20]$.

Some studies suggest that physicians consciously and subconsciously incorporate racial information about patients into their communication styles and decision making [21-23], but limited research has examined clinicians' attitudes towards the relationship between race and genetic variation in clinical decision making [24]. Understanding how primary care physicians think about the intersection of race and genetics is critical for health disparities and health services research given the current racial and ethnic inequities in healthcare, the advancements of genomic medicine, and its early translation to health care.

This gap in the literature is, in part, due to a lack of reliable and valid measures to assess the role of race and genetics in clinical decision making processes. In order to assess these complex relationships, new measures, with good psychometric properties, are needed. To this end, we developed the Genetic Variation Knowledge Assessment Index (GKAI) to assess physicians' scientific knowledge of genetic variation, the Health Professionals Beliefs about Race (HPBR) scale to measure health professionals' beliefs about genetic difference, and the Racial Attributes in Clinical Evaluation (RACE) scale to investigate health professionals' use of race in clinical practice. ${ }^{a}$

In this paper, we describe the process used to develop these scales; specifically, we present a brief description of the Physicians Understanding of Human Genetic Variation (PUHGV) Study, summarize the conceptual model used to guide the process, and briefly outline the activities that generated the items used in the final scales. Finally, we describe in detail the final confirmatory phase undertaken to characterize each new measure.

\section{Conceptual model}

To guide the scale development process, we developed a conceptual model aimed at exploring the use of race ${ }^{\mathrm{b}}$ and genetic variation in clinical decision making (Figure 1). Our model derives from an extensive literature review and interviews with health care providers, representing an integration of critical race theory, social cognition theory, and the empirical literatures on clinical decision making, provider behavior, and the role of genetics and genomics in complex disease risk [1,22,25-35].

The model consists of six domains: characteristics of provider and patient; provider knowledge and beliefs; patient knowledge and beliefs ${ }^{\mathrm{c}}$; the clinical encounter; interpretation; and the clinical decision. These domains foreground a seventh domain which we describe as the racial lens.

The model suggests that this racial lens is a social frame that influences the cognitive processes within all aspects of the clinical decision making process in the USA context, from the clinical encounter through synthesis of data to the final diagnostic and treatment decisions. The social frame of the racial lens permeates the clinical decision making process, is integrated both explicitly and implicitly by provider and patient, and furthers several hypotheses related to the role of race in clinical decision making. For example, it is possible that race is most influential in the interpretation and clinical decision phases, especially when genetic and molecular data are unavailable. Perhaps health professionals with greater knowledge of the science of genetic ancestry and genetic variation and its importance in diagnosis and treatment will use molecular and genomic information differently than health professionals who do not have that body of scientific knowledge [36]. Our model also suggests that genetic and molecular data could play an important role in challenging the racial lens and possibly taking the clinical encounter and thereby other domains of the clinical decision making process in directions that a racialized clinical encounter may not. It is possible that health professional's knowledge and beliefs about race and human genetic variation could improve or could encumber their interpretation and clinical decision. We found, for example, a positive association between physicians' anxiety due to uncertainty and self-reported use of race in their clinical decision making [37].

Thus, it is particularly important to study how physicians and other health professionals interpret and utilize race in their clinical decision making. We developed scales to measure the domains of physician knowledge and beliefs about race and human genetic variation and physician's use of race in the domains of interpretation and clinical decision (see conceptual model). These measures were developed as part of the Physicians Understanding of Human Genetic Variation (PUHGV) Study. 




The final scales presented in this report were developed within a three phased project designed to understand physicians' knowledge of human genetic variation and the role of race in the clinical decision making process. In the first phase, focus groups with 90 general internists in the USA who self-identified as either black or white were conducted in order to gain insight into providers' opinions on the use of race in clinical decision making and their views on the relationship between race, genetics, and disease [20,38,39]. Findings from these focus groups were used to develop items for the scales. We conducted 30 semi-structured cognitive interviews with general internists to assist in the development and revision of these items. Items were further refined based on guidance from two panels of experts (geneticists and survey methodologists).

In Phase II, a pilot instrument, including the three scales, was tested with a national random sample of 364 general internists. Exploratory factor analysis (EFA) was used to help diagnose areas of poor fit and to identify items with low (<.5) loadings. Items with low loadings were eliminated from the item pool and only those items with validity and strong theoretical bases were included as items in the final scales. The revised scales were then assessed by three physicians to ensure clarity and consistency among the core concepts. The current article details the methods and resulting scales from Phase III of the study.

\section{Methods}

\section{Sample}

The data were collected between April-December 2010; the survey was administered via the web and mail to a national sample of 2122 clinically active general internists. The sample was drawn from the SK\&A company's AMA Masterfile physician database in 2 batches. First, a general random sample $(n=1929)$ general internists of all racial and ethnic backgrounds was selected from the overall database. This was supplemented by a sample of physicians who graduated from historically black medical schools $(n=193)$ in an effort to increase the representation of black physicians in the overall sample and improve the study's ability to detect differences between black physicians and other physicians. We excluded physicians who were not currently practicing general internists according to their office staff or did not have a current (USA) mail address, and identified a sample size of 1,738 eligible physicians.

Respondents received a $\$ 50$ incentive for participating. Potential respondents received six reminders over a six month period to complete the web survey. After six contacts, non-responding physicians were sent a paper version of the survey instrument and their offices were 
contacted to verify the receipt of the final mailing. Of the 787 total completed surveys, 108 (13.76\%) were completed and returned using the paper questionnaire. Analysis indicated no significant differences between mail and web respondents. The overall response rate for the survey was $45.35 \%$.

This study was reviewed and approved by the National Human Genome Research Institute Institutional Review Board (05-HG-N196). The Principal Investigator requested and obtained a waiver of requiring a signed consent from each participant in the study. Participants viewed a statement that described the goals of the study, protection of personally identifiable information, and a statement that the survey was voluntary and they could withdraw at anytime. The participant checked a box that read "I agree to participate" upon checking the box the participant could begin the survey.

\section{Survey instrument and scale development}

In Phase III, the scale items were included in a nationwide, multi-mode (web-based survey with a mail survey sent to non-responders) survey of practicing general internists concerning their knowledge and clinical application of genetics and genomics. The Health Professionals' Genetics Education Needs Exploration (HP GENE) Survey included 81 -items that included the items for three scales and 57 additional items. The final instrument consisted of six sections: (1) scientific knowledge of human genetic variation; (2) beliefs regarding genetics, race, and ethnicity; (3) consideration of race in clinical practice; (4) genetics and genomics in your clinical practice; (5) clinical decision making approaches; and, (6) demographic information. The three sections related to the scales are described below. ${ }^{\mathrm{d}}$

Section 1: Scientific knowledge of human genetic variation. In this section (Table 1), respondents answered true or false to questions such as "the DNA sequences of two randomly selected healthy individuals of the same sex are $90-95 \%$ identical." The items in the knowledge scale were scored true/false, with a "don't know" category. "Don't know" was considered an incorrect response for analytic purposes. Scores for knowledge were obtained by summing the correct responses. Higher scores indicated a greater knowledge of human genetic variation.

Section 2: Beliefs regarding genetics, race, and ethnicity. This section comprised nine items (Table 2) used to assess physicians' beliefs regarding the relationship between race and genetics such as "A patient's race can identify patients who can benefit from enhanced screening for certain diseases." The items were rated on a 5point Likert-type scale $(5=$ strongly agree to $1=$ strongly disagree).

Section 3: Consideration of race in clinical practice. This section of the survey included eight items (Table 3) to assess the degree to which health professionals employ race in their clinical decision making processes such as "I consider my patients' race when making decisions about which medications to prescribe." The item response categories were on a 5 -point Likert-type scale $(4=$ all of the time to $0=$ none of the time).

\section{Analysis}

Descriptive statistics were calculated for the items associated with all three scales. Confirmatory factor analysis (CFA) was performed using AMOS 18 to evaluate the measurement models for the Health Professionals Beliefs about Race (HPBR) and Racial Attributes in Clinical Evaluation (RACE) scales, to identify measurement model changes and to validate each of the resulting scales. EFA was used to help diagnose areas of poor fit and to revise the scales for HPBR.

Table 1 Items for the genetic variation knowledge assessment index (GKAI)

\begin{tabular}{|c|c|c|}
\hline ITEM\# & QUESTION & ${ }^{+}$ANSWER \\
\hline GKAl1 & $\begin{array}{l}\text { The DNA sequences of two randomly selected healthy individuals of the same sex are } \\
90-95 \% \text { identical. }\end{array}$ & False $(22 \%)^{* *}$ \\
\hline GKAI2 & Most common diseases, such as diabetes and heart disease, are caused by a single gene variant. & False (80\%) \\
\hline GKAI3* & $\begin{array}{l}\text { Common structural genetic variation (changes in the human genome such as deletions, } \\
\text { duplications and large-scale copy-number variants) is important in health and disease. }\end{array}$ & True $(90 \%)$ \\
\hline GKAI4 & $\begin{array}{l}\text { All the genetic variation in an individual can be attributed to either spontaneous (i.e., de novo) } \\
\text { or inherited changes in the human genome. }\end{array}$ & True (60\%) \\
\hline GKAI5* & $\begin{array}{l}\text { The variation in the human genome includes both disease-causing gene variants and variants } \\
\text { that have no effect on health and disease. }\end{array}$ & True $(92 \%)$ \\
\hline GKAI6 & Individual genetic variants are usually highly predictive of the manifestation of common disease. & False (60\%) \\
\hline GKAI7 & Prevalence of many Mendelian diseases differs by racial groups. & True (69\%) \\
\hline GKAI8 & Self-reported race is informative of a racial group's genetic ancestral background. & True (39\%) \\
\hline
\end{tabular}

*Item not included in final scoring.

${ }^{\dagger}$ Correct answer.

${ }^{* *}$ Numbers in parentheses indicate the percentage of respondents who answered the question correctly. 
Table 2 Items and standardized factor loadings for the Health Professionals Beliefs about Race (HPBR) scale

\begin{tabular}{|c|c|c|}
\hline ITEM & QUESTION & LOADING \\
\hline \multicolumn{3}{|c|}{ Biological domain } \\
\hline HPBR-BD1 & $\begin{array}{l}\text { Genetics usually explains differences in the prevalence of common diseases, such as diabetes and } \\
\text { kidney disease, among racial groups. }\end{array}$ & .53 \\
\hline HPBR-BD2 & National Census categories of race correspond with genetic differences. & .53 \\
\hline HPBR-BD3 & Race is the best proxy clinicians have to identify genetic effects on health. & .68 \\
\hline HPBR-BD4 & A clinician's best predictor of treatment response is the patient's self-identified race. & .67 \\
\hline HPBR-BD5* & A patient's race provides important information about a patient's risk of disease. & \\
\hline \multicolumn{3}{|c|}{ Clinical domain } \\
\hline HPBR-CD1 & A patient's race can identify patients who can benefit from enhanced screening for certain diseases. & .61 \\
\hline HPBR-CD2 & A patient's race can identify patients who can benefit from referral to genetic services for certain diseases. & .71 \\
\hline HPBR-CD3 & $\begin{array}{l}\text { Human genetic variation provides clues to unraveling the primary causes of specific racial and ethnic } \\
\text { disparities in health. }\end{array}$ & .47 \\
\hline HPBR-CD4* & There are genetic differences in racial groups that influence health. & \\
\hline
\end{tabular}

*Item not included in final scoring.

Biological Domain (HPBR-BD) and Clinical Domain (HPBR-CD).

\section{Results}

\section{Respondents}

The demographic characteristics of the respondents $(\mathrm{N}=787)$ can be found in Table 4 . The sample consisted of almost twice as many males $(65.3 \%)$ as females (34.7\%) and $75.4 \%$ graduated from a medical school in the USA. While $88.7 \%$ of the respondents indicated that they did not receive genetics training in their primary specialty training, $84.7 \%$ indicated that their knowledge of genetics was fair or better. The majority of respondents (59.1\%) practice primarily in an office setting, spend an average of 85\% (SD $=19.4 \%)$ of their time seeing patients and have an average of 16.4 ( $\mathrm{SD}=9.6$ ) years in practice post training.

Table 4 compares the demographics of our survey respondents with demographic data available from the AMA Physician Masterfile [40]. On those demographics that permit comparison, the survey respondents appear to reflect the profile of physicians in the AMA data except that there appears to be a higher percentage of whites in our sample than indicated in the AMA data. Noting that $27.4 \%$ of the AMA data has an unknown race, it is likely that some of these physicians are white which would then better reflect the percentage of whites in our sample.

\section{Scale analysis \\ Genetic variation knowledge assessment index (GKAl)}

An initial analysis of the responses of the items in the Genetic Variation Knowledge Assessment Index (GKAI) indicated that over $90 \%$ of the responses for two items (GKAI3 and GKAI5) were correct. These items were deleted from the scale as they did not sufficiently differentiate respondents (Table 1). The GKAI was created by summing the number of correct responses of the remaining items. The resulting GKAI covers the full range from zero to six, has a mean of $3.28(\mathrm{SD}=1.17)$ and is roughly symmetric and unimodal. The GKAI has statistically significant correlation with only one item of the

Table 3 Items and standardized factor loadings for the Racial Attributes in Clinical Evaluation (RACE) Scale

\begin{tabular}{lll}
\hline ITEM\# & QUESTION & LOADINGS \\
\hline RACE1 & I consider information from patients about their racial background. & .61 \\
RACE2 & I consider my patients race to better understand their genetic predispositions. & .69 \\
RACE3 & I consider my patients race when making decisions about which medications to prescribe. & .74 \\
RACE4 & I consider my patients race in determining genetic risk for common, complex diseases & .77 \\
RACE5 & (e.g. kidney disease or diabetes). \\
RACE6 & I consider my patients race in making medication dosage decisions. \\
RACE7 & I consider my patients race when determining age of initiation of screening for certain diseases. \\
RACE8* & I consider my patients race in determining how aggressively to treat particular diseases. & .64 \\
& I consider my patients race in determining genetic risk for single gene conditions \\
\hline
\end{tabular}

*Item not included in final scoring. 
Table 4 Characteristics of physician respondents and U.S. internal medicine physicians

\begin{tabular}{|c|c|c|c|c|c|}
\hline Sample characteristics $^{\dagger}$ & $\mathrm{N}$ & $\%$ & Mean & SD & $\mathrm{AMA}^{*}(\%)$ \\
\hline Total internal medicine physicians & 787 & -- & -- & -- & \\
\hline Mean age & 767 & -- & 48.6 & 9.6 & -- \\
\hline \multicolumn{6}{|l|}{ Gender } \\
\hline Male & 505 & 65.3 & -- & -- & 67.2 \\
\hline Female & 269 & 34.7 & -- & -- & 32.8 \\
\hline \multicolumn{6}{|l|}{ Ethnicity } \\
\hline Hispanic/Latino & 27 & 3.5 & -- & -- & 4.9 \\
\hline \multicolumn{6}{|l|}{ Race } \\
\hline White & 515 & 67.1 & -- & -- & 44 \\
\hline Black or African-American & 49 & 6.4 & -- & -- & 3.9 \\
\hline Asian & 160 & 20.8 & -- & -- & 17.4 \\
\hline American Indian/Alaska Native & 9 & 1.2 & -- & -- & 0.1 \\
\hline Native Hawaiian/Pacific Islander & 2 & 0.3 & -- & -- & -- \\
\hline Other & 54 & 7 & -- & -- & 2.3 \\
\hline \multicolumn{6}{|l|}{ Are you a graduate of US Medical School? } \\
\hline Yes & 584 & 75.4 & -- & -- & -- \\
\hline No & 190 & 24.5 & -- & -- & -- \\
\hline \multicolumn{6}{|c|}{ Did you have genetics training in primary specialty residency? } \\
\hline Yes & 87 & 11.3 & -- & -- & -- \\
\hline No & 684 & 88.7 & -- & -- & -- \\
\hline Mean years in practice post-training & 769 & -- & 16.4 & 9.6 & -- \\
\hline \multicolumn{6}{|l|}{ Primary practice setting } \\
\hline Academic health center & 89 & 11.4 & -- & -- & -- \\
\hline Federally Qualified Health Center & 23 & 2.9 & -- & -- & -- \\
\hline Group or staff model practice HMO & 62 & 7.9 & -- & -- & -- \\
\hline Hospital based & 105 & 13.5 & -- & -- & -- \\
\hline Office based & 459 & 59.1 & -- & -- & -- \\
\hline VA healthcare system & 15 & 1.9 & -- & -- & -- \\
\hline Other & 24 & 3.1 & -- & -- & -- \\
\hline \multicolumn{6}{|l|}{ Affiliation with academic institution? } \\
\hline Yes & 304 & 39.2 & -- & -- & -- \\
\hline No & 471 & 60.8 & -- & -- & -- \\
\hline Percentage of work time seeing patients & 772 & 85 & -- & -- & -- \\
\hline \multicolumn{6}{|c|}{ How would you rate your knowledge of genetics? } \\
\hline Excellent & 4 & 0.5 & -- & -- & -- \\
\hline Very good & 36 & 4.6 & -- & -- & -- \\
\hline Good & 184 & 23.7 & -- & -- & -- \\
\hline Fair & 433 & 55.9 & -- & -- & -- \\
\hline Poor & 118 & 15.2 & -- & -- & -- \\
\hline
\end{tabular}

${ }^{\dagger}$ Questions taken from the Health Professionals' Genetics Education Needs Exploration (HP GENE) Survey.

${ }^{*} \mathrm{~N}=160,107$. Data taken from the AMA's Physician Characteristics and Distribution in the US book, 2010 Edition.

-- Data not available.

HPBR scale and one item of the RACE scale. In both cases, these correlations are small and could be considered random occurrences.
Health professionals beliefs about race (HPBR) scale A CFA indicated that our initial hypothesis of a single scale was not supported by the data (Table $2 \&$ Figure 2). 


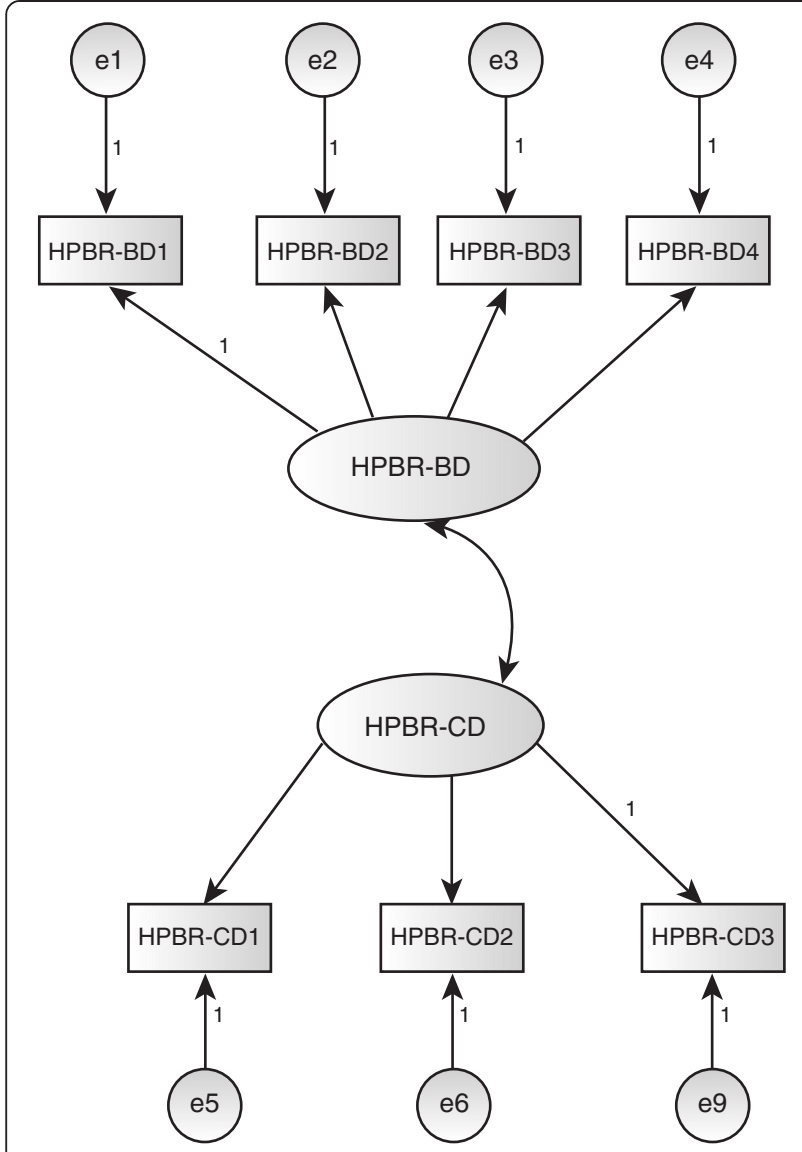

Figure 2 Health Professional Beliefs and Race Scale (HPBR). The scale consists of two domains representing beliefs about race as a biological phenomenon (HPBR-BD) and beliefs about the clinical importance of race (HPBR-CD). Confirmatory Factor Analysis for this model indicated that a correlation between the errors associated with items HPBR-BD1 and HPBR-CD3 should be included (the highest interpretable modification index).

A subsequent EFA suggested that the HPBR scale consisted of two domains representing beliefs about race as a biological phenomenon (HPBR-BD) and beliefs about the clinical importance of race (HPBR-CD). The Cronbach's alpha for the items included in the biological domain (HPBR-BD) was .69 and for the clinical domain (HPBR-CD) was .61, both of which are at the lower end of the range generally considered acceptable. A CFA for this model (Figure 2) was fit and the diagnostics indicated that a correlation between the errors associated with items HPBR-BD1 and HPBR-CD3 should be included. The resulting CFA was evaluated using a variety of measures [41]. The chi-square (43.6 with 12 degrees of freedom and $\mathrm{p}<.001$ ) was significant but this could have been a result of the large sample size $(\mathrm{n}=761){ }^{\mathrm{e}}$ Other measures such as the GFI (.984), AGFI (.92), CFI (.96) and RMSEA (.059) all indicated an adequate fit to the data. The item loadings were all positive and statistically significant $(\mathrm{p}<.001)$ and the correlation was also positive and statistically significant $(\mathrm{p}<.001)$. The standardized loadings for HPBR-BD ranged from .53 to .68 resulting in communalities ranging from .28 to .46 . The average variance extracted for HPBR-BD was .36 and the reliability was .69 . The standardized loadings for HPBR-CD ranged from .47 to .71 resulting in communalities ranging from .22 to .50 . The average variance extracted for HPBR-CD was .37 and the reliability was .64. The correlation between HPBR$\mathrm{BD}$ and HPBR-CD is .58 and the two constructs satisfy discriminant validity. Both constructs extract less than half the variance associated with their measurement variables. This can be linked to the generally low levels of correlation (loadings) between the measurement variables and their constructs. These results suggest that the convergent validity for the constructs HPBR-BD and HPBR-CD is not as strong as typically desired. In consideration of the potential similarity between the correlated items HPBR-BD1 and HPBR-CD3, we refit the model without HPBR-BD1 and found that the fit characteristics of the resulting model along with the resulting loadings were not materially different. Consequently, we opted to present the current model.

The correlation between the HPBR-BD and HPBR-CD scales and the GKAI scale is .07 and .07 respectively. While the correlation between HPBR-BD and GKAI is just significant at the .05 level (.045) this is consistent with the large sample size and the possibly random correlations noted above.

\section{Racial attributes in clinical evaluation (RACE) scale}

Our initial hypothesis regarding the Racial Attributes in Clinical Evaluation (RACE) scale included all items indicated in Table 3. A CFA and associated diagnostics indicated that RACE8 should be dropped (Figure 3) and that correlations between the errors associated with items RACE1 and RACE2 and between the errors associated with items RACE5 and RACE7 should be added, which we did to be consistent with the theoretical intent of the scale. Incorporating these changes, Cronbach's alpha for the remaining items used to measure the RACE scale is .86. The subsequent CFA model fit was evaluated using a variety of measures. The chi-square (46.4 with 12 degrees of freedom and $\mathrm{p}<.001$ ) was significant but this could have been a result of the large sample size $(\mathrm{n}=761)$. Other measures such as the GFI (.984), AGFI (.963), CFI (.984) and RMSEA (.061) all indicated an adequate fit to the data. The final loadings were all positive and statistically significant $(\mathrm{p}<.001)$ and the error correlations $(\rho($ RACE1, RACE2 $)=.424, \rho($ RACE5, RACE7 $)=.174)$ were also positive and statistically significant $(\mathrm{p}<.001)$. The standardized loadings ranged from .61 to .77 resulting in communalities ranging from .38 to .59 . The average variance extracted was .46 and the reliability was .85 . These 


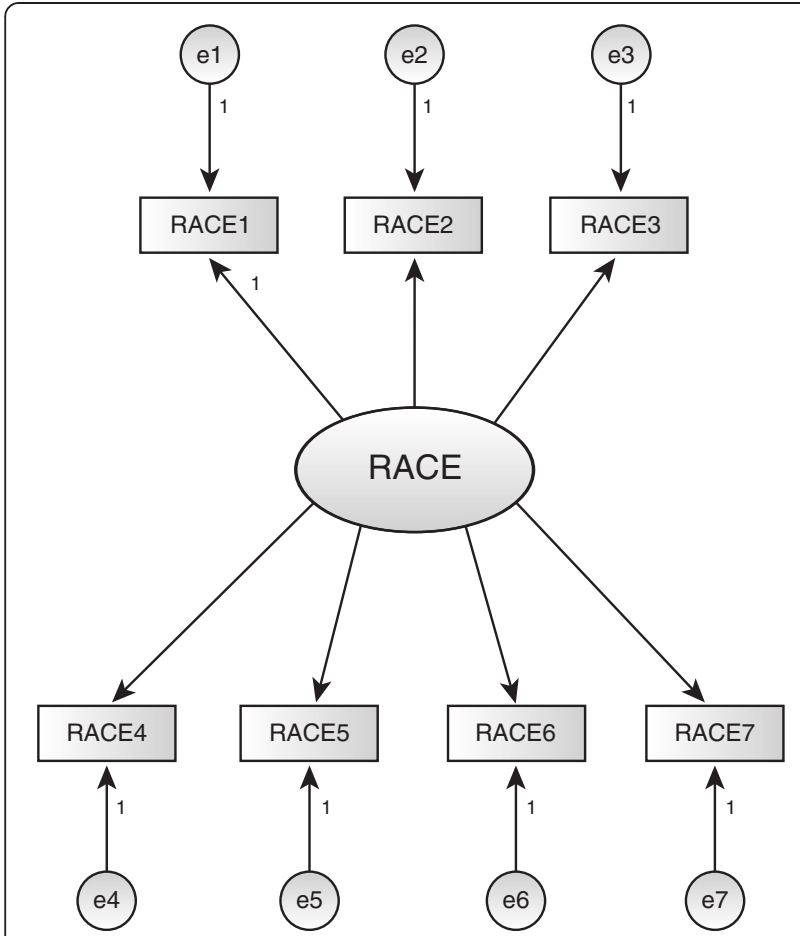

Figure 3 Racial Attributes in Clinical Evaluation Scale (RACE).

The scale consists of one domain representing the explicit use of race. Confirmatory Factor Analysis for this model indicated an adequate fit to the data. There were no particularly large modification indices and no additional justifiable parameters were indicated.

results support convergent validity of the construct [41]. The correlation of .07 between RACE and GKAI is insignificant $(\mathrm{p}>.05)$ while there is a significant correlation of .51 and .50 with HPBR-BD and HPBR-CD respectively.

\section{Discussion}

We developed three measures that assess physicians' knowledge and beliefs about genetics and genetic variation and the use of race in clinical decision making. These scales were the outgrowth of the PUHGV study qualitative research phase $[20,38,39]$ and a conceptual model which aimed to facilitate exploration about how physicians' understanding of genetic variation and race might influence the clinical process (Figure 1). We believe that the measures have the potential to lead to new insights into the intersections of race, genetics, and health.

The Genetic Variation Knowledge Assessment Index (GKAI) measures health professionals' knowledge of human genetic variation, in contrast to health professionals' perceived knowledge (in analysis not shown, the correlation between GKAI and physicians' self-reported rating of their knowledge of genetics was .16). The GKAI was developed to measure specific domains of factual knowledge including concepts that are deemed important by professional organizations [42]. The GKAI could be administered as a pre-post assessment of health professional knowledge of race and genetic variation.

In contrast to measuring scientific knowledge, the beliefs scales aimed to tap into often implicit assumptions about race, although these assumptions may be drawn from experiential knowledge. The belief scales aim to capture an important, though somewhat understudied and under theorized area of medical decision making. Analysis of items to measure beliefs about race suggested two domains, one related to beliefs about race as a biological phenomenon (HPBR-BD) and the other related to beliefs about the clinical value of race and genetic variation for understanding individual and group-level risk for disease (HPBR-CD); neither scale exhibited strong psychometric properties. It is possible that there are too few items to adequately measure the constructs. Nonetheless, the HPBR is an important step in developing a measure that captures health professionals' beliefs about the role of race in clinical practice. With further development, the HPBR may be useful for both designing interventions and in evaluating them. The scale could be used in clinical settings to aid health care providers in more explicitly articulating their beliefs about race. A clearer articulation of racial beliefs could help health care professionals better tailor care plans to individual patients [43] and communicate the complex concept of genetic variation to the general public. Future research would also do well to more explicitly link beliefs about race with knowledge about racial inequality and social causes of health disparities.

The RACE scale, developed to assess the use of race in clinical practice, had good psychometric properties. Having a valid and reliable measure of physicians' use of race has a number of important applications. For example, the RACE scale could be utilized in cultural competency curricula to explore the use of race in clinical care. With the goal of reducing racial and ethnic health disparities in recent years, there has been an increase in cultural competency training in the health professions. Although varied in curricular and content areas, these interventions target some aspects of knowledge, attitudes/beliefs, and behaviors of health care professionals [44]. Cultural competency training seeks to impact knowledge, skills and behaviors of health care professionals, but few interventions use objective assessments to measure changes in behavior [44]. The RACE scale measures self-reported behaviors and to our knowledge is the first measure of its kind. The RACE scale intentionally does not provide the respondent a definition of race. The measure was developed for the survey respondent to answer the items based upon their own interpretation of "race" and how they use it in clinical practice. The scale is a useful tool for assessing health care 
provider decision making and as a tool for use in health professionals' education.

More broadly, the appropriate use of race in clinical decision making remains contested [8] and the RACE scale aims to provide empirical data to address this debate. On one hand, use of race may heighten physicians' recognition of social and cultural experiences of the patient and assist with clinical diagnoses based upon varying prevalence of diseases and conditions. On the other, using race may preclude personalized medicine and have lifethreatening implications for failure to diagnose a disease. The value of the RACE scale is that it has the potential to measure the use of race in clinical decision making.

\section{Limitations}

This study has four important limitations that merit discussion and further research. These limitations are related to the sample, survey response rate, the sociopolitical context in which race, genetics and health are embedded, and the exploratory nature of the study. The sample was limited to primary care physicians in the USA. General internists were selected because they are on the frontlines of health care delivery and many treat adult patients with diverse backgrounds, health concerns and risk profiles. Nonetheless, the sample is not representative of all physicians. Differences in specialty, discipline, types of responsibilities, even practice volume might affect attitudes and beliefs. Nor does the sample include other health care professionals (e.g., nurses) who are also on the frontlines of healthcare services to diverse populations. For these reasons, the findings from this study cannot be generalized. Researchers who wish to use the new measures to study health professionals globally will need to establish reliability and validity for those study populations.

A number of strategies were used to maximize survey returns [45]; nonetheless the response rate was 45\%, a rate not uncommon in physician surveys. Although limitations related to nonresponse are recognized in this study, the similarity of the demographics between the sample and the AMA database of physicians (see Table 4) provides some evidence that our sample is representative.

In the USA, discourse about race in general and race and genetics in particular can be controversial [38]. Respondents may have been uncomfortable with some of the survey items resulting in non-response or socially desirable responses. We excluded only 26 cases with incomplete responses on the scale items and, as far as we could determine, these appeared to be responses missing at random. Further, we aimed to minimize the likelihood of socially desirable response bias through use of web, careful consideration of question order and wording, and use of expert panels, focus groups, and cognitive interviews.
Our findings require additional research and confirmation. While researchers can employ the RACE scale with confidence about its reliability, the HPBR scale had low convergent validity. Additional validity studies are also needed for the GKAI. Further study might examine whether physicians with more knowledge of human genetic variation hold more nuanced understanding of the role of race and ethnicity in health, and whether that understanding is associated with clinical decision making.

\section{Conclusions}

Our measures make explicit the sometimes unarticulated assumptions about relationships between race, genetics, and health. Specifically we suggest that there is a complex association between knowledge of human genetic variation, beliefs about race and genetics, and use of race in clinical decision making processes. Developing measures that assess these three dimensions are needed if medical educators and health professionals are to move forward in efforts to understand, teach, practice, and evaluate the associations between genomics and race.

These scales provide a tool to explore how physicians think about the role of race and genomics in clinical care and the use of race in treatment decisions. The scales can be used to evaluate and assess knowledge and beliefs in medical and health professional education and continuing training. As we explore implicit attitudes of race with physicians and medical students [22,23] we must also examine explicit use of race in clinical care and health care providers' explicit attitudes and beliefs about the importance of race in a clinical setting.

Medical advances and social and demographic changes put pressure on the skills and knowledge of the primary care physician and other health care professionals and can challenge their ability to provide comprehensive care for patients of different social, cultural, and ancestral backgrounds. With genomic and personalized medicine we may someday move beyond race and ethnicity as a surrogate for genetic variation in health care. To move beyond race, will require health care providers to have the skills to communicate to their patients the complex concepts of population groups and human genetic variation [46]. Currently however, race and ethnicity serve as proxies for factors we are only beginning to understand about the relationships between genetic variation and health, thus in this interim, we need to deepen our understanding of health care providers understanding of race and genetic variation and use of race in their decision making. We anticipate that our measures will contribute to ongoing debates about race, racial health disparities, and genetics. The measures introduced here provide researchers an opportunity to explore explicit use of race in clinical decision making and could provide new insights into health professionals' knowledge and beliefs about race, genetics, and health. 


\section{Endnotes}

${ }^{a}$ The official titles of the scales are Bonham and Sellers Genetic Variation Knowledge Assessment Index (GKAI), Bonham and Sellers Health Professionals Beliefs about Race (HPBR) scale, and the Bonham and Sellers Racial Attributes in Clinical Evaluation (RACE) scale. ${ }^{\mathrm{b}}$ The conceptual model and scale development focused on the concept 'race' and not 'ethnicity' because beliefs about and use of 'race' have an important and complex history within science and medicine in the USA.

${ }^{\mathrm{C}}$ The patient has an important role in clinical decisions. The focus of the current paper is on the role of the provider. Future work will consider patient domains.

${ }^{d}$ Future research will use the remaining sections to validate the scales.

${ }^{\mathrm{e}}$ Twenty-six cases with incomplete responses on the scale items were excluded from analysis.

\section{Competing interests}

The authors have no financial or non-financial competing interests.

\section{Authors' contributions}

VLB conceived of the Physicians Understanding of Genetic Variation Study (PUHGV) and led the design of the HP-GENE Survey. He supervised the project and coordinated the analysis, and contributed extensively in writing of all drafts of the manuscript. SLS led the writing team in the manuscript preparation, as well as contributed to all aspects of the quantitative analysis. SW conducted the quantitative analysis, contributed significantly to manuscript development and revised critical sections of the paper for content. All authors read and approved the final manuscript.

\section{Acknowledgements}

The authors wish to acknowledge the experts that participated in the survey and scale development advisory groups and the primary care physicians, and geneticists who provided guidance and input in the scale development. The authors would like to also acknowledge our colleagues for their input and feedback on the manuscript. Special thanks to Abt Associates for their research support particularly Amanda Parsad for statistical assistance.

\section{Funding}

This research was supported [in part] by the Intramural Research Program of the National Human Genome Research Institute, National Institutes of Health (ZIA HG200324-07).

\section{Disclosures}

The content is solely the responsibility of the authors and does not represent the official position of the National Human Genome Research Institute, National Institutes of Health or Department of Health and Human Services.

\section{Author details}

${ }^{1}$ Social and Behavioral Research Branch, National Human Genome Research Institute, National Institutes of Health, 31 Center Drive, Bethesda, MD 20892, USA. ${ }^{2}$ University Department of Family Studies \& Social Work, Miami University, 210 East Spring Street, Oxford, OH 45056, USA. ${ }^{3}$ Department of Mathematical Sciences, Director, Center for Quantitative Analysis, Bentley University, Waltham, MA, USA.

Received: 6 January 2014 Accepted: 18 September 2014 Published: 2 October 2014

\section{References}

1. Bamshad M: Genetic influences on health: does race matter? JAMA 2005 294:937-946.

2. Bliss C: Race Decoded, The Genomic Fight for Social Justice. Stanford: Stanford University Press; 2012.
3. Knerr S, Wayman D, Bonham VL: Inclusion of racial and ethnic minorities in genetic research: advance the spirit by changing the rules? J Law Med Ethics 2011, 39:503-512.

4. Fujimua JH, Rajagopalan R: Different differences: the use of 'genetic ancestry' versus race in biomedical human genetic research. Soc Stud Sci 2011, 41:5-30.

5. Hunt LM, Megyesi MS: The ambiguous meanings of the racial/ethnic categories routinely used in human genetics research. Soc Sci Med 2008, 66(2):349-361

6. Shim JK: "Constructing 'race' across the science-lay divide: racial formation in the epidemiology and experience of cardiovascular disease. Soc Stud Sci 2005, 35:405-436.

7. Duster T: Social diversity in humans: implications and hidden consequences for biological research. Cold Spring Harb Perspect Biol 2014, 6:a008482.

8. Barr DA: The practitioner's dilemma: can we use a patient's race to predict genetics, ancestry, and the expected outcomes of treatment? Ann Intern Med 2005, 143:809-815.

9. Rotimi CN, Jorde LB: Ancestry and disease in the age of genomic medicine. N Engl J Med 2010, 363:1551-1558.

10. Collins FS: What we do and don't know about 'race', 'ethnicity', genetics and health at the dawn of the genome era. Nat Genet 2004, 36(Suppl 11):S13-S15.

11. Tang H, Quertermous T, Rodriguez B, Kardia SL, Zhu X, Brown A, Pankow JS, Province MA, Hunt SC, Boerwinkle E, Schork NJ, Risch NJ: Genetic structure, self-identified race/ethnicity, and confounding in case-control association studies. Am J Hum Genet 2005, 76:268-275.

12. Zakharia F, Basu A, Absher D, Assimes TL, Go AS, Hlatky MA, Iribarren C, Knowles JW, Li J, Narasimhan B, Sidney S, Southwick A, Myers RM, Quertermous T, Risch N, Tang H: Characterizing the admixed African ancestry of African Americans. Genome Biol 2009, 10:R141.

13. Braun L, Fausto-Sterling A, Fullwiley D, Hammonds EM, Nelson A, Quivers W, Reverby SM, Shields AE: Racial categories in medical practice: how useful are they? PLoS Med 2007, 4:e271

14. Burchard EG, Ziv E, Coyle N, Gomez SL, Tang H, Karter AJ, Mountain JL, Perez-Stable EJ, Sheppard D, Risch N: The importance of race and ethnic background in biomedical research and clinical practice. N Engl J Med 2003, 348:1170-1175.

15. Cohn JN: The use of race and ethnicity in medicine: lessons from the African-American Heart Failure Trial. J Law Med Ethics 2006, 34:552-554. 480.

16. Cooper RS, Kaufman JS, Ward R: Race and genomics. N Engl J Med 2003, 348:1166-1170.

17. Williams DR, Sternthal M: Understanding racial-ethnic disparities in health: sociological contributions. J Health Soc Behav 2010, 51(Suppl 1):S15-S27.

18. van Ryn M, Burgess D, Malat J, Griffin J: Physicians' perceptions of patients' social and behavioral characteristics and race disparities in treatment recommendations for men with coronary artery disease. Am J Public Health 2006, 96:351-357

19. Braun L: Reifying human difference: the debate on genetics, race, and health. Int J Health Serv 2006, 36:557-573.

20. Frank D, Gallagher TH, Sellers SL, Cooper LA, Price EG, Odunlami AO, Bonham VL: Primary care physicians' attitudes regarding race-based therapies. J Gen Intern Med 2010, 25:384-389.

21. Burgess DJ, Van Ryn M, Crowley-Matoka M, Malat J: Understanding the provider contribution to race/ethnicity disparities in pain treatment: insights from dual process models of stereotyping. Pain Med 2006, 7:119-134.

22. Green AR, Carney DR, Pallin DJ, Ngo LH, Raymond KL, lezzoni LI, Banaji MR: Implicit bias among physicians and its prediction of thrombolysis decisions for black and white patients. J Gen Intern Med 2007, 22:1231-1238.

23. Haider AH, Sexton J, Sriram N, Cooper LA, Efron DT, Swoboda S, Villegas CV, Haut ER, Bonds M, Pronovost PJ, Lipsett PA, Freischlag JA, Cornwell EE 3rd: Association of unconscious race and social class bias with vignette-based clinical assessments by medical students. JAMA 2011, 306:942-951.

24. Warshauer-Baker E, Bonham VL, Jenkins J, Stevens N, Page Z, Odunlami A, McBride CM: Family physicians' beliefs about genetic contributions to racial/ethnic and gender differences in health and clinical decisionmaking. Community Genet 2008, 11:352-358.

25. Ford CL, Airhihenbuwa CO: Critical Race Theory, race equity, and public health: toward antiracism praxis. Am J Public Health 2010, 100(Suppl 1):S30-S35. 
26. van Ryn M, Fu SS: Paved with good intentions: do public health and human service providers contribute to racial/ethnic disparities in health? Am J Public Health 2003, 93:248-255.

27. Walsh JM, McPhee SJ: A systems model of clinical preventive care: an analysis of factors influencing patient and physician. Health Educ Q 1992, 19:157-175.

28. Smedley BD, Stith AY, Nelson AR: Unequal Treatment: Confronting Racial and Ethnic Disparities in Health Care. Washington, DC: National Academies Press; 2003.

29. VanRyn M, Burke J: The effect of patient race and socioeconomic status on physicians' perceptions of patients. Soc Sci Med 2000, 50:813-828

30. Johnson RL, Roter D, Powe NR, Cooper LA: Patient race/ethnicity and quality of patient-physicians communication during medical visits. Am J Public Health 2004, 94:2084-2090.

31. Sabin JA, Rivara FP, Greenwald AG: Physician implicit attitudes and stereotypes about race and quality of medical care. Med Care 2008, 46:678-685.

32. Dovido JF, Gaertner SL, Dovido JF, Gaertner SL: Aversive racism and selection decisions: 1988 and 1989. Psychol Sci 2000, 11:315-319.

33. Tversky A, Kaheman D: Judgment under uncertainty: heuristics and biases. Science 1974, 185:1124-1131.

34. Coop-Patrick L, Gallo JJ, Gonzales JJ, Vu HT, Powe NR, Nelson C, Ford DE: Race, gender, and partnership in the patient-physician relationship. JAMA 1999, 282:583-589.

35. Rotimi CN, Jorde LB: Ancestry and disease in the age of genomic medicine. N Engl J M 2012, 363:1551-1558.

36. The National Academies: Toward Precision Medicine: Building a Knowledge Network for Biomedical Research and a New Taxonomy of Disease. Washington, D.C: National Academies Press; 2011.

37. Cunningham BA, Bonham VL, Sellers SL, Yeh HC, Cooper LA: Physicians' anxiety Due to uncertainty and Use in medical decision-making. Med Care 2014, 52:728-733.

38. Bonham VL, Sellers SL, Gallagher TH, Frank D, Odunlami AO, Price EG, Cooper LA: Physicians' attitudes toward race, genetics, and clinical medicine. Genet Med 2009, 11:279-286.

39. Snipes SA, Sellers SL, Tafawa AO, Cooper LA, Fields JC, Bonham VL: Is race medically relevant? A qualitative study of physicians' attitudes about the role of race in treatment decision-making. BMC Health Serv Res 2011, 11:183.

40. Smart D: Physician Characteristics and Distribution in the US. Chicago: American Medical Association Press: 2010.

41. Hair JF, Black WC, Babin BJ, Anderson RE: Multivariate Data Analysis. Prentice Hall: Upper Saddle River; 2010.

42. Core competencies for All health care professionals. http://www.nchpeg org/index.php?option=com_content\&view=article\&id $=237 \&$ ltemid $=84$

43. Weisse CS, Sorum PC, Sanders KN, Syat BL: Do gender and race affect decisions about pain management? J Gen Intern Med 2001, 16:211-217.

44. Beach MC, Price EG, Gary TL, Robinson KA, Gozu A, Palacio A, Smarth C, Jenckes MW, Feuerstein C, Bass EB, Powe NR, Cooper LA: Cultural competence: a systematic review of health care provider educational interventions. Med Care 2005, 43:356-373.

45. Dillman DA: Mail and Internet Surveys: The Tailored Design Method. New York: Wiley; 2000.

46. Bussey-Jones J, Henderson G, Garrett J, Moloney M, Blumenthal C, Corbie-Smith G: Asking the right questions: views on genetic variation research among Black and White research particpants. J Gen Intern Med 2008, 24:299-304.

doi:10.1186/1472-6963-14-456

Cite this article as: Bonham et al:: Physicians' knowledge, beliefs, and use of race and human genetic variation: new measures and insights. BMC Health Services Research 2014 14:456.

\section{Submit your next manuscript to BioMed Central and take full advantage of:}

- Convenient online submission

- Thorough peer review

- No space constraints or color figure charges

- Immediate publication on acceptance

- Inclusion in PubMed, CAS, Scopus and Google Scholar

- Research which is freely available for redistribution

Submit your manuscript at www.biomedcentral.com/submit
Biomed Central 